\title{
FORWARD PREMIUMS AND MARKET EFFICIENCY: Panel Unit-root Evidence from the Term Structure of Forward Premiums
}

\author{
John Barkoulas \\ Department of Economics \\ The University of Tennessee \\ Knoxville, TN 37996 \\ Christopher F. Baum \\ Department of Economics \\ Boston College \\ Chestnut Hill, MA 02467-3806 \\ Atreya Chakraborty \\ Charles River Associates \\ 200 Clarendon Street, T-33 \\ Boston, MA 02116-5092
}

\begin{abstract}
A plausible explanation for cointegration among spot currency rates determined in efficient markets is the existence of a stationary, time-varying currency risk premium. Such an interpretation is contingent upon stationarity of the forward premium. However, empirical evidence on the stochastic properties of the forward premium series has been inconclusive. We apply a panel unit-root test-the Johansen likelihood ratio (JLR) test-to forward exchange premiums by utilizing cross-sectional information from their term structure. In contrast to earlier studies, the JLR test provides decisive and temporally stable evidence in support of stationary forward premiums, and therefore foreign exchange market efficiency, for six major currencies.
\end{abstract}

Keywords: Forward premium, currency risk premium, panel unit-root tests, foreign exchange market efficiency

JEL Classification: F30, F31 


\section{FORWARD PREMIUMS AND MARKET EFFICIENCY: Panel Unit-root Evidence from the Term Structure of Forward Premiums}

\section{Introduction}

The weak-form efficiency hypothesis of foreign exchange markets presents testable implications for the time series behavior of systems of spot currency rates. ${ }^{1}$ Researchers' empirical findings of cointegration in systems of spot exchange rates (Alexander and Johnson (1992), Lopez (1996), and Baillie and Bollerslev (1989, 1994a), inter alia) would seem to contradict the market efficiency hypothesis, since a cointegrated system necessarily implies the presence of predictability of returns in at least one currency. ${ }^{2,3}$

Does the existence of cointegration among spot rates imply a rejection of the market efficiency hypothesis? ${ }^{4} \quad$ Crowder (1994) argues that the cointegrating relationship may merely reflect a common feature: a time-varying currency risk premium evident in several currencies' returns. ${ }^{5}$ Under conditions of risk aversion, foreign exchange market efficiency implies that a time-varying risk premium must share the same stochastic properties with the error-correction term from the cointegrated system, that is, it must be covariance stationary. Since the risk premium is unobservable, its stochastic properties cannot be directly ascertained, but it can be shown that they depend on the order of integration of the forward premium. Therefore, the finding of a stationary forward premium would directly imply stationarity of the currency risk premium, which would be compatible with the temporal behavior of the error correction term from a cointegrated system of spot exchange rates. Our investigation of the foreign exchange market efficiency 
hypothesis thus proceeds from a study of the stochastic properties of forward premiums.

The empirical evidence on the stochastic properties of forward premiums is decidedly mixed. Using daily data for four currencies, Crowder (1992) finds that forward premium series are nonstationary processes. Crowder (1994) confirms such unit-root evidence for monthly forward premium series for three currencies, and concludes that the data do not support the market efficiency hypothesis. Luintel and Paudyal (1998) find daily forward premium series for five currencies to be realizations of unit-root processes, while Horvath and Watson (1995) and Clarida and Taylor (1997) reach the conclusion that forward premiums are stationary processes. Baillie and Bollerslev (1994b) report that the forward premium series are best characterized as neither $I(1)$ nor $I(0)$ processes, but as fractionally integrated processes.

In this paper, we place this issue in sharper contrast by employing more powerful tests of the stationarity hypothesis for forward premium series. The contradictory findings in the literature may reflect the well-known limited power of conventional unit-root tests against stationary alternatives in small samples. In contrast, we evaluate these relationships by employing a panel unit-root test. Compared with individual time series, panels of series contain more observations and greater total series variation. We strengthen the power of our tests by utilizing the cross-sectional information available in the term structure of forward exchange premiums. To test the unit-root hypothesis, we employ the Johansen likelihood ratio (JLR) test, a multivariate unit-root test recently proposed by Taylor and Sarno (1998), which offers important methodological advantages over first-generation panel unit-root tests. Applying the JLR test to daily observations for six major currencies over panels of 1-, 3-, 6- and 12-month contract maturities, we obtain decisive and temporally stable rejections of the unit-root hypothesis for forward 
exchange premiums. This evidence stands in sharp contrast to the mixed empirical findings in the literature, and is consistent with foreign exchange market efficiency under conditions of risk aversion.

The plan of the paper is as follows. Section 2 presents the analytics of the forward premium and the implications of its stochastic structure for foreign exchange market efficiency. In Section 3, we present details of the test employed, while Section 4 presents our empirical findings. Conclusions and further implications for empirical research are discussed in the final section.

\section{Analytics of the Forward Premium}

We briefly present below the theoretical basis underlying the connection between the time-series dynamics of the forward premium and the foreign exchange market efficiency hypothesis in its weak form. Under conditions of risk aversion in the foreign exchange market, it follows that

$$
f_{t}=E_{t}\left(S_{t+m}\right)+r p_{t, m}
$$

where $f_{t}$ is the $\log$ forward rate at time $t$ for delivery $m$ periods later, $S_{t+m}$ is the corresponding log spot rate at time $t+m, r p_{t, m}$ is a time-varying risk premium on forward contracts, and $E_{t}($.$) is the mathematical expectations operator conditioned on$ the time- $t$ available information set. A risk premium exists if risk-averse economic agents demand compensation above expected spot rate depreciation for holding forward contracts and is hypothesized to be a source of the forward rate bias. ${ }^{6}$ Assuming that expectations of foreign exchange spot rates are rational,

$$
S_{t+m}=E_{t}\left(S_{t+m}\right)+u_{t+m}
$$


where $u_{t+m}$ the rational expectations realized forecast error, must have a conditional expected value of zero and be uncorrelated with any information available at time $t$ (the orthogonality condition). Substituting (2) into (1) yields

$$
f_{t}=S_{t+m}+r p_{t, m}-u_{t+m} .
$$

The future spot rate may be rewritten as the sum of the current spot rate and the future change, which when incorporated into (3) yields

$$
f_{t}-S_{t}=\left(S_{t+m}-S_{t}\right)+r p_{t, m}-u_{t+m} .
$$

Thus, the forward premium is decomposed into three components: the spot return, the forward risk premium, and the rational expectations error term. Since currency spot rates are best characterized as martingales, the spot returns series $S_{t+m}-S_{t}$ is a martingale-difference $(I(0)$, or stationary) process. The rational expectations forecast error $u_{t+m}$ is an $I(0)$ process by definition. Consequently, the order of integration of the forward risk premium, $r p_{t, m}$, in (4) is contingent upon the order of integration of the forward premium, $f_{t}-S_{t}{ }^{7}$

The stochastic structure of $r p_{t, m}$, and therefore of $f_{t}-S_{t}$ given equation (4), has important implications for the weak-form efficiency hypothesis in the foreign exchange market. Given that a number of studies establish evidence of cointegration in systems of spot exchange rates, it follows from the Granger representation theorem that the returns series for at least one currency in the cointegrated system must be predictable on the basis of the error correction term (disequilibrium error). Such predictability might profitably be exploited and thus would constitute a 
violation of the weak-form market efficiency hypothesis, thereby linking the concepts of cointegration and market efficiency.

Crowder (1994) argues that the predictability of the cointegrated currency spot rates derived from the error correction term may not be a violation of foreign exchange market efficiency if the error correction term serves as a proxy for a currency risk premium. This explanation would be empirically confirmed if the risk premium, consistent with the time series properties with the error correction term, is a covariance stationary process. However, barring any other explanation for the presence of common stochastic trends among spot exchange rates, nonstationary dynamics (unit roots) in the currency risk premium would imply a violation of the foreign exchange market efficiency hypothesis, as the stationary error correction term could not possibly serve as an instrument for a nonstationary currency risk premium. Given equation (4), the integration order of the forward premium has direct implications for the stochastic structure of the currency risk premium and, consequently, for foreign exchange market efficiency.

\section{The Johansen Likelihood Ratio (JLR) Test}

Johansen (1992) suggests a maximum likelihood method to determine the number of common trends in a system of unit-root variables. Without any loss of generality, a $p$-dimensional vector autoregressive (VAR) process of $k$-th order can be written as follows:

$$
\Delta X_{t}=\mu+\Theta_{1} \Delta X_{t-1}+\ldots+\Theta_{k-1} \Delta X_{t-k+1}+\Pi X_{t-k}+\varepsilon_{t}
$$




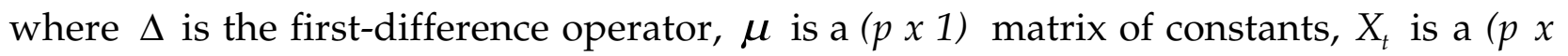
1) random vector of time-series variables with order of integration of at most one, $\varepsilon_{t}$ is a sequence of zero-mean $p$-dimensional white noise vectors, $\Theta_{i}$ are $\left(\begin{array}{lll}p & x & p\end{array}\right)$ matrices of parameters, and $\Pi$ is a $\left(\begin{array}{l}p \\ x\end{array} p\right)$ matrix of parameters, the rank of which contains information about long-run relationships among the variables in the VAR. ${ }^{8}$ Expression (5) is referred to as the vector error correction model (VECM).

If $\Pi$ has full rank, that is, $\operatorname{rank}(\Pi)=p$, then all variables in the system are stationary. If the rank of $\Pi$ is zero, then no cointegrating vectors exist. In the case of $0<r<p, r$ cointegrating vectors exist. In this case, there exist $(p \times r)$ matrices $\alpha$ and $\beta$ such that $\Pi=\alpha \beta^{\prime} . \beta$ is the matrix of cointegrating vectors and has the property that $\beta^{\prime} X_{t}$ is stationary even though the $\mathrm{X}_{t}$ may be individually $I(1)$ processes. Following Sarno and Taylor (1998) and Taylor and Sarno (1998), the null hypothesis that one or more of the system processes are nonstationary can take the form of

$$
H_{0}: \operatorname{rank}(\Pi)<p
$$

and be tested against the alternative that all system processes are stationary, that is,

$$
H_{1}: \operatorname{rank}(\Pi)=p .
$$

To test the hypothesis in (6), it suffices to test whether the smallest of the characteristic roots of $\Pi$ is zero, as a rejection necessarily implies that all characteristic roots of $\Pi$ are nonzero and therefore $\Pi$ possesses full rank. Such a test can be constructed on the basis of the following test statistic, referred to as the Johansen likelihood ratio (JLR) test statistic:

$$
J L R=-T \ln \left(1-\lambda_{p}\right),
$$


where $\lambda_{p}$ is the smallest eigenvalue of the generalized eigenvalue problem

$$
\left|\lambda S_{k k}-S_{k 0} S_{00}{ }^{-1} S_{0 k}\right|=0 .
$$

The $S_{i j}$ matrices are residual moment matrices from the VECM in (5). Taylor and Sarno (1998) show that the JLR test statistic in (8) is asymptotically distributed as $\chi^{2}(1)$ under the null hypothesis.

The JLR multivariate test employed here offers important methodological advantages over first-generation panel-unit root tests proposed by Levin and Lin (1992, 1993), Im et al. (1995), O'Connell (1998), and others. Such tests have as their null hypothesis that all variables in the panel are realizations of unit-root processes. Hence, this null will be rejected if even one of the series in the panel is stationary. Under these conditions, rejection of the unit-root null can be driven by a few stationary series and the whole panel may erroneously be modeled as stationary. The rejection frequencies for such tests are sizable even when there is a single stationary process with a near-unit root among a system of otherwise unit-root processes (Taylor and Sarno (1998)). ${ }^{9}$ The JLR test differs fundamentally from the firstgeneration panel-unit root tests in terms of its null and alternative hypotheses. In the JLR test the null is that at least one of the series in the panel is a unit-root process with the alternative being that all series in the panel are stationary processes. Thus, rejection of the null hypothesis implies that all (not some) of the series are realizations of stationary processes. Therefore, inference drawn from the JLR test should be more reliable as it avoids the potential pitfalls inherent in standard panel unit-root tests. 


\section{Data and Test Results}

We analyze daily U.S. dollar spot and 1, 3-, 6-, and 12-month forward rates for six major currencies: Canadian dollar (CD), Deutsche mark (DM), British pound (BP), French franc (FF), Italian lira (IL), and the Japanese yen (JY). The sample period spans 01/02/1980 to $12 / 31 / 1998$ for a total of 4,848 observations. Our sample period ends with the advent of the Euro, the single currency of the European Monetary Union, which was originally adopted by 11 member states from January $1,1999 .{ }^{10}$ These rates represent noon-time U.S.-dollar quotes from the New York exchange market and were obtained from the Federal Reserve Board of Governors and Datastream. The forward premium series are constructed as differences of the logarithms of forward and spot rates.

Given the conflicting findings of previous studies based on univariate unitroot tests or cointegration tests in $\left(f_{t}, S_{t}\right)$ systems, we apply the JLR panel unit-root test to systems of forward premium series. By exploiting cross-equation dependencies and increasing the span of the data by jointly testing for a unit root across a number of series, multivariate tests are likely to lead to substantial gains in efficiency and test power.

We construct our panels of time series so as to exploit the information content of the term structure of forward exchange premiums. This methodology is in contrast to most applications of panel unit-root tests in the literature, in which the panel dimension indexes individual countries or assets. The typical panel for currency $j$ consists of the vector of variables $y_{t}^{j}=\left[f_{m(1)}^{j}-s_{t}^{j}, f_{m(3)}^{j}-s_{t}^{j}, f_{m(6)}^{j}-s_{t}^{j}, f_{m(12)}^{j}-s_{t}^{j}\right]$, where $f_{m(1)}^{j}, f_{m(3)}^{j}, f_{m(6)}^{j}$, and $f_{m(12)}^{j}$

are time- $t \log$ forward rates with contract maturities of $1,3,6$, and 12 months, respectively, and $s_{t}^{j}$ is the log spot exchange rate at time $t$. 
Table 1 reports the contemporaneous cross-equation residual correlation matrix among the AR-filtered forward premium series in each panel. The contemporaneous correlation matrix for the AR residuals demonstrates strong crossequation effects in the data, which is confirmed by the statistically significant LM test statistics for the diagonality of the covariance matrix. Given the presence of strong cross-equation dependencies, systems estimation is expected to yield substantial efficiency gains.

Before we proceed with the implementation of the JLR test, we apply a univariate test for the integration order of the forward premium series. We perform the efficient test for an autoregressive unit root suggested by Elliott, Rothenberg, and Stock (ERS, 1996). Their test, referred to as the ADF-GLS test, is similar to the augmented Dickey-Fuller $t$ test as it applies GLS detrending before the (detrended) series is tested via the Dickey-Fuller regression. Compared with the ADF tests, the ADF-GLS test has the best overall performance in terms of small-sample size and power. It "has substantially improved power when an unknown mean or trend is present" (ERS, p. 813).

Table 2 presents the ADF-GLS test results for the demeaned series. ${ }^{11,12} \mathrm{We}$ report test statistics for several lag lengths to ensure robustness of the inference drawn. For the $C D$ series, the evidence is consistent with stationary behavior for the forward premiums at the 1- and 3-month contract horizons but weakly so at the longer tenors. With the possible exception of the 1-month contract maturity, the evidence overwhelmingly supports the presence of a unit root in the DM forward premium series. For the $\mathrm{BP}, \mathrm{FF}$, and IL the forward premium series appear to be realizations of stationary processes for all contract maturity lengths. Finally, the forward exchange premiums for the JY appear to exhibit stationary stochastic behavior for the 1-month maturity but nonstationary behavior for the rest of maturities. The overall evidence based on the univariate ADF-GLS unit-root test 
suggests that the stochastic structure of forward premiums varies across currency and forward contract maturities. ${ }^{13}$

Table 3 reports the JLR test results for the panels of forward exchange premiums at various term structures for the currencies under consideration. The JLR test statistic is asymptotically distributed as $\chi^{2}(1)$; however, we account for finitesample bias by adjusting the asymptotic critical value by the Reinsel-Ahn scale factor $T /(T-p k)$, where $T$ is the number of observations, $p$ is the number of series in the panel (dimension of the system), and $k$ is the lag order in the VECM in (5). Using response surface analysis, Taylor and Sarno (1998) show that such an adjustment produces a reasonable approximation to the finite-sample critical values, thus avoiding significant size distortions. Statistical significance is indicated with respect to the adjusted critical values. The JLR test statistic is calculated for a variety of lag lengths in the VECM in (5), ranging from $k=4$ to $k=48$. The values of the obtained JLR test statistics exceed the corresponding adjusted critical values, at better than 5 per cent levels, for all lag-length specifications across currencies except for certain VECM lag-orders for the DM (in which the null hypothesis is rejected at the 10 per cent level). For our sample currencies, the null hypothesis that the matrix of longrun multipliers is less than full rank (implying that one or more of the system variables is a nonstationary process) is strongly rejected in favor of a full rank impact matrix, thus implying that the stochastic evolution of the forward exchange premiums at all maturity horizons is consistent with that of a stationary process. ${ }^{14,15}$ Spot and forward rates (at all maturities) exhibit a homogeneous cointegrating relationship, that is, they form cointegrated systems with $(1,-1)$ cointegrating vectors.

Compared with the inference drawn from the (univariate) ADF-GLS test, the JLR test results confirm the evidence of stationarity for the BP, FF, and IL forward exchange premiums. For the CD, DM, and JY series, the JLR test supports stationary 
stochastic behavior contrary to the inference drawn from univariate ADF-GLS tests. This reflects the power deficiencies of the univariate test in small samples and the substantial efficiency and power gains attained from systems estimation.

One issue of concern regarding the integration order of forward premiums is the temporal stability of the inference. To analyze the structural stability of the evidence across time, we re-estimate the JLR test statistics over an initial sample ending on 10/28/1993 and subsequently on samples generated by adding sixty-six observations (approximately a quarter's worth of observations) until the total sample is exhausted. Figure 1 graphs the JLR test statistics for the various subsamples. ${ }^{16}$ These recursive test statistics do not fluctuate noticeably and maintain their statistical significance over time. The test statistics for the DM are generally significant at the 10 per cent level and the evidence becomes increasingly supportive of stationary forward premia with expanded sample size. Overall the recursive JLR test statistics clearly point toward dynamic stability and provide strong evidence against the hypothesis that the forward premiums contain a unit root. Therefore, the possibility that the predictability implied by the cointegrability of spot exchange rates reflects the predictability implied by a currency risk premium cannot be eliminated.

\section{Conclusions}

We apply the JLR test, a multivariate unit-root test, to panels of forward premium series that exploit dependencies in the term structure of forward exchange premiums, rather than cross-country variation. In contrast to much of the empirical literature, we find decisive evidence that the forward premiums for six major currencies (at all tenors considered) are stationary processes. We attribute the contradictory findings in previous studies to the low statistical power of the conventional, univariate unit-root tests they employed. Our findings have several 
implications. First, stationary forward exchange premiums help reconcile the cointegration of currency spot rates with the hypothesis of weak-form foreign exchange market efficiency (under risk aversion) à la Crowder (1994). The presence of common stochastic trends among spot exchange rates could serve as proxies for a currency risk premium. Second, given that the forward premium reflects the stochastic structure of the currency risk premium, our findings support stationary behavior for the risk premia of our sample currencies (relative to the U.S. dollar), which is justifiable on theoretical grounds. ${ }^{17}$ Finally, domestic and foreign nominal interest rate differentials are stationary processes, given the covered interest rate arbitrage condition in the international financial markets.

\section{Acknowledgement}

We are grateful to two anonymous reviewers and the editor for their constructive suggestions on an earlier draft. The usual disclaimer applies. 


\section{References}

Alexander, C. O. and A. Johnson (1992), Are foreign exchange markets really efficient? Economics Letters, 40, 449-453.

Baillie, Richard T. and Tim Bollerslev (1989), Common stochastic trends in a system of exchange rates, Journal of Finance, 44, 167-181.

Baillie, Richard T. and Tim Bollerslev (1994a), Cointegration, fractional cointegration, and exchange rate dynamics, Journal of Finance, 49, 737-745.

Baillie, Richard T. and Tim Bollerslev (1994b), The long memory of the forward premium, Journal of International Money and Finance, 13, 565-571.

Bossaerts, Peter (1988), Common non-stationary components of asset prices, Journal of Economic Dynamics and Control, 12, 347-364.

Cerchi, Marlene and Arthur Havenner (1988), Cointegration and stock prices: The random walk on Wall Street revisited, Journal of Economic Dynamics and Control, 12, 333-346.

Clarida, Richard and Mark P. Taylor (1997), The term structure of forward exchange premiums and the forecastibility of spot exchange rates: Correcting the errors, Review of Economics and Statistics, 353-361.

Crowder, William J. (1992), Spot and forward exchange rates and the efficiency of foreign exchange markets, working paper, University of Texas at Arlington.

Crowder, William J. (1994), Foreign exchange market efficiency and common stochastic trends, Journal of International Money and Finance, 13, 551-564.

Crowder, William J. (1996), A note on cointegration and international capital market efficiency: A reply, Journal of International Money and Finance, 15, 661-664.

Dwyer, Gerald P., Jr. and Myles Wallace (1992), Cointegration and market efficiency, Journal of International Money and Finance, 11, 318-327. 
Elliott, Graham, T. Rothenberg, and James Stock (1996), Efficient tests for an autoregressive unit root, Econometrica, 64, 813-836.

Engel, Charles (1996a), The forward discount anomaly and the risk premium: A survey of recent evidence, Journal of Empirical Finance, 3, 123-192.

Engel, Charles (1996b), A note on cointegration and international capital market efficiency, Journal of International Money and Finance, 15, 657-660.

Engle, Robert F. and Clive W. Granger (1987), Cointegration and error correction: Representation, estimation, and testing, Econometrica, 55, 251-276.

Horvath, Michael and Mark Watson (1995), Testing for cointegration when some of the cointegrating vectors are prespecified, Econometric Theory, 11, 984-1015.

Im, Kyong So, Pesaran, M. Hashem, and Yongcheol Shin (1995), Testing for unit roots in heterogeneous panels, unpublished paper, Department of Applied Economics, University of Cambridge.

Johansen, Soren (1992), Cointegration in partial systems and the efficiency of single equation analysis, Journal of Econometrics, 52, 389-402.

Karlsson, Sune and Mickael Löthgren (2000), On the power and interpretation of panel unit root tests, Economics Letters, 66, 249-255.

Levin, Andrew and Chien-Fu Lin (1992), Unit root tests in panel data: Asymptotic and finite sample properties, discussion paper no. 92-93, Department of Economics, University of California, San Diego.

Levin, Andrew and Chien-Fu Lin (1993), Unit root tests in panel data: New results, discussion paper no. 93-56, Department of Economics, University of California, San Diego.

Lopez, Jose (1996), Exchange rate cointegration across central bank regime shifts, Federal Reserve Bank of New York, research paper 9602.

Luintel, K. B. and K. Paudyal (1998), Common stochastic trends between forward and spot exchange rates, Journal of International Money and Finance, 17, 279-297. 
Ng, Serena and Pierre Perron (1995), Unit root tests in ARMA models with datadependent methods for the selection of the truncation lag, Journal of the American Statistical Association, 90, 268-281.

Nyblom, Jukka and Andrew Harvey (2000), Tests of common stochastic trends, Econometric Theory, 16, 176-199.

O'Connell, Paul (1998), The overvaluation of purchasing power parity, Journal of International Economics, 44, 1-20.

Sarno, Lucio and Mark P. Taylor (1998), Real exchange rates under the recent float: Unequivocal evidence of mean reversion, Economics Letters, 60, 131-137.

Schwert, G. William (1989), Tests for unit roots: A Monte Carlo investigation, Journal of Business and Economic Statistics, 7, 147-160.

Sephton, Peter and Hans Larsen (1991), Tests of exchange market efficiency: Fragile evidence from cointegration tests, Journal of International Money and Finance, 10, 561-570.

Taylor, Mark P. and Lucio Sarno (1998), The behavior of real exchange rates during the post-Bretton Woods period, Journal of International Economics, 46, 281312. 


\section{Notes}

${ }^{1}$ The weak form of asset market efficiency states that no asset price should be forecastable from the prices of other assets.

2 According to the Granger representation theorem (Engle and Granger (1987)), cointegration implies the existence of Granger-causal orderings among cointegrated time series. While deviations from equilibrium dissipate, they impact the short-run dynamics of the set of asset prices, implying predictability of an asset price on the basis of the others. Such predictability suggests the existence of arbitrage opportunities across markets.

3 Sephton and Larsen (1991) caution that evidence of cointegration among spot exchange rates exhibits instability as it is sensitive to model specification and choice of sample period.

${ }^{4}$ Bossaerts (1988) and Dwyer and Wallace (1992) challenge the theoretical basis for the presumed relationship between market efficiency and cointegration. Engel (1996b) and Crowder (1996) further debate the issue. Cerchi and Havenner (1988) provide evidence of increased predictability for stock prices of five department stores based on their cointegrating relationship with one dominant common trend.

5 The presence of a time-varying foreign exchange risk premium is one possible explanation for the cointegration of spot exchange rates. As Crowder (1994) points out, peso problems, learning, regime shifts, or other unobserved factors consistent with rational behavior in an efficient foreign exchange market could provide alternative plausible explanations. 
${ }^{6} r p_{t, m}$ represents in fact a risk premium only if economic agents have rational expectations (in that sense, termed a rational expectations risk premium). In a broader context, deviations between forward rates and corresponding future spot rates could reflect risk aversion and/or the absence of rational expectations.

${ }^{7}$ Nonstationarity of the forward premium would imply that the commonly estimated regression of future spot currency depreciation on the forward premium is not a "balanced" regression in the sense of Engle and Granger (1987).

8 The rank of a matrix is equal to the number of its nonzero characteristic roots.

9 Karlsson and Löthgren (2000) also warn that, in using standard panel unit-root tests, "The acceptance or rejection of the null is thus not sufficient evidence to conclude that all series have a unit root or that all are stationary." (p. 249)

10 Among the European currencies in our sample, only BP is not a participating currency in the Euro-zone.

11 The maximum lag order for the test is calculated from the sample size according to the rule provided by Schwert (1989) using $c=12$ and $d=4$ in his terminology.

12 The inference drawn is not materially altered if the ADF-GLS test is applied to the detrended forward premium series.

13 Even though this evidence is broadly consistent with previously reported results, it does offer stronger evidence in support of stationarity for the forward exchange premiums. This may be attributed to the greater statistical power of the ADF-GLS test (as compared to the standard ADF test) and clearly points to the lack of power of univariate testing for unit roots in forward exchange premiums. Moreover, given the fragmentary and disparate evidence of stationarity from univariate unit-root 
tests, one cannot comfortably conclude that forward premiums for major currencies are stationary stochastic processes and draw the theoretical implications from such a finding. This provides clear motivation for the application of multivariate unit-root testing in forward currency premiums.

14 We also subjected our panels of forward premium series to the multivariate augmented Dickey-Fuller (MADF) test, a multivariate analogue to the standard, univariate ADF unit-root test. For all our panels and across all orders of serial correlation considered, the MADF test rejects the null hypothesis of joint nonstationarity in favor of the alternative that at least one of the series in the panel is generated by a stationary process. As mentioned earlier, these rejections should be interpreted with caution as they do not imply that the series in each panel form a stationary vector process. However, the JLR test results do have the strong implication that the forward premium series are each realizations of stationary processes. The MADF test results are not reported, but are available from the authors on request.

15 To further validate our empirical findings, we employed the test of Nyblom and Harvey (2000). This multivariate test has a null hypothesis that there are $K<N$ common trends in a set (or panel) of $N$ time series. If $K=0$ is specified, the NyblomHarvey test (like the well-known KPSS test for a single series) has a null hypothesis of stationarity against the alternative that at least one random-walk component is present. For all our panels and across orders of serial correlation, the test fails to reject the null that there are no common trends, or random-walk components, at 
any conventional level of significance. The Nyblom-Harvey test results are not reported, but are available from the authors on request.

16 To conserve space, we graph in Figure 1 the evolution of the JLR test statistics for VECM lag-length specification of order 36. The temporal behavior of the JLR test statistics is robust to alternative VECM lag orders for all currency panels (these results are available upon request).

${ }^{17}$ From a theoretical viewpoint, it is difficult to believe that a currency risk premium would follow a nonstationary process, as there is no asset pricing model that predicts stochastic trending behavior for the currency risk premium. For example, timevarying risk premiums based on equilibrium models reflect second moments of the relevant macroeconomic variables (see Engel (1996a) for a comprehensive review of this literature). 
Table 1. Correlation Analysis of Forward Exchange Premiums

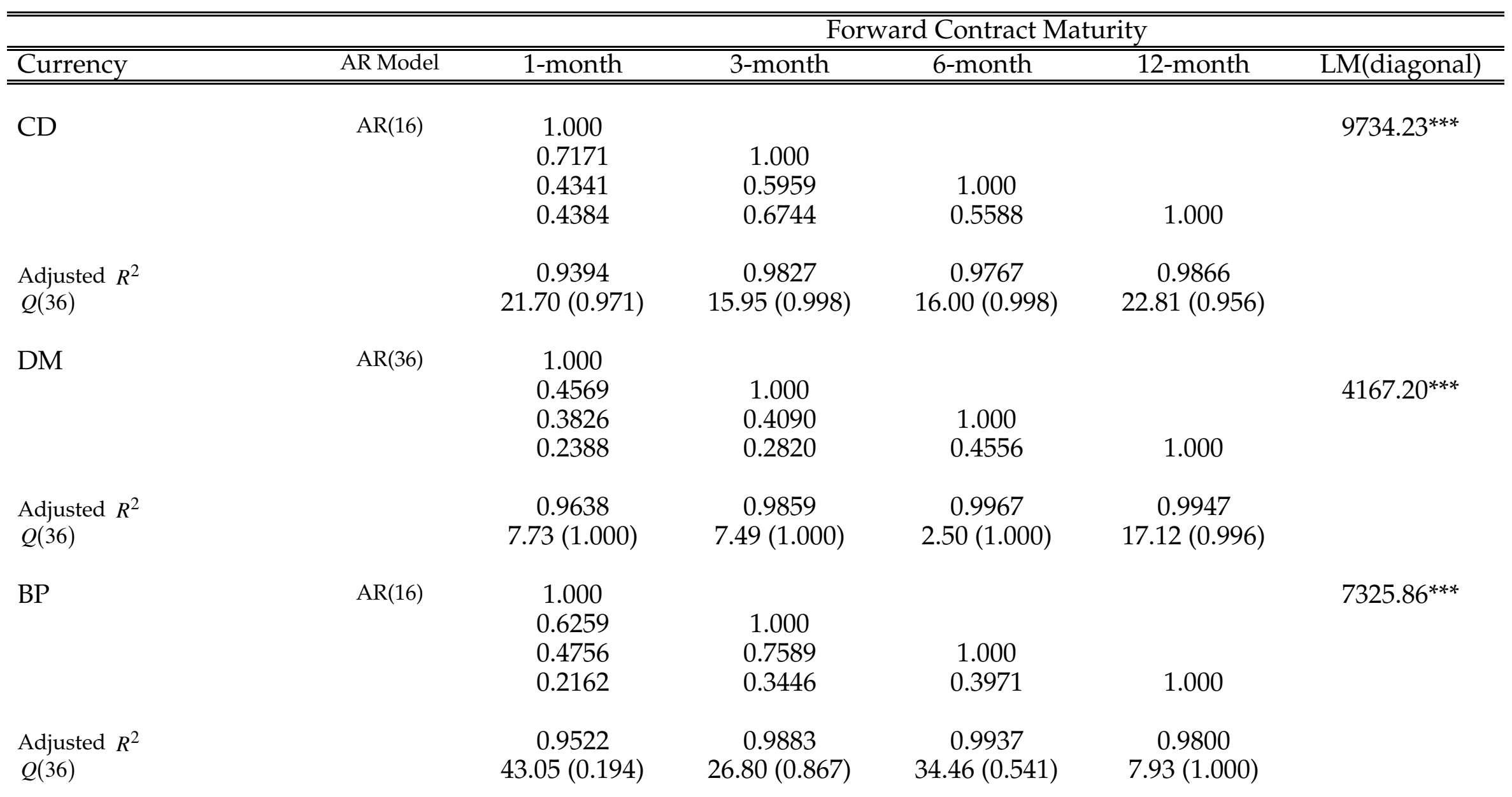


Adjusted $R^{2}$ $Q(36)$

$39.53(0.314)$

IL

Adjusted $R^{2}$

$Q(36)$

JY
$\operatorname{AR}(24)$

\subsection{0}

0.8697

0.8830

0.5841

0.3840

$27.23(0.853)$

AR(28)

\subsection{0}

\subsection{5}

0.2872

0.1774
40.19 (0.289)

0.9844

$50.02(0.060)$

1.000

0.8742

0.5871

0.7580

$36.93(0.425)$

0.6509
(0.425)

1.000
0.6616
0.4317

1.000

0.4317
1.000

0.6756

\subsection{9}

$28.60(0.805)$

1.000

0.4984
0.9825
0.9707

$31.06(0.702)$

1.000

0.9874

40.51 (0.278)

$16593.27^{* * *}$

0.9166
$.85(0.172)$

0.9166
$43.85(0.172)$

1.000

$5630.22^{* * *}$

1.000

$6.83(1.000)$

\subsection{7}

$Q(36)$

5.44 (1.000)

$4.37(1.000)$

Notes: The data are the forward premium (discount) series $f_{t}-S_{t}$, where $f_{t}$ is the log forward rate at time $t$ for delivery date $t+m$ and $S_{t}$ is the spot rate at time $t$, for the Canadian dollar (CD), Deutsche mark (DM), British pound (BP), French franc (FF), Italian lira (IL), and the Japanese yen (JY). The contract maturities considered are for $m=1,3,6$, and 12 months. The data are daily observations covering the period $01 / 02 / 1980$ to $12 / 31 / 1998$. The correlation matrices were constructed from the residual vectors obtained from the AR regressions indicated in column 2. $Q(36)$ is the Box-Pierce $Q$-test statistic for autocorrelation of order 36 in the residual series obtained from the AR regressions indicated in column 2. The $\mathrm{LM}$ (diagonal) test is the Lagrange multiplier statistic $T \sum_{i=2}^{n} \sum_{j=1}^{i-1} r_{i j}^{2}$ for the null hypothesis that the off-diagonal elements of the relevant correlation matrix are zero, where $r_{i j}$ is the $i j$ th residual correlation coefficient. The LM test is $\chi^{2}$ distributed with $p(p-1) / 2$ degrees of freedom, where $p$ is the number of series, and it is $\chi^{2}(6)=16.81$ at the 1 per cent level in our case. ${ }^{* * *}$ indicates statistical significance at the 1 per cent level. 
Table 2. ADF-GLS Unit-root Test Results

\begin{tabular}{|c|c|c|c|c|c|c|c|c|c|}
\hline & \multicolumn{9}{|c|}{ Lag Order } \\
\hline Currency & $k=8$ & $k=16$ & $k=24$ & $k=36$ & $k=44$ & & MAIC & \multicolumn{2}{|c|}{$\begin{array}{c}\text { Sequential- } t \\
\text { Criterion }\end{array}$} \\
\hline \multicolumn{10}{|l|}{$\overline{\mathrm{CD}}$} \\
\hline 1-month & $-2.835^{* * *}$ & $-2.996^{* * *}$ & $-2.806^{* * *}$ & $-2.793^{* * *}$ & $-2.860 * * *$ & (19) & $-2.803^{* * *}$ & (47) & $-2.729 * * *$ \\
\hline 3-month & $-2.446^{* *}$ & $-2.568^{* *}$ & $-2.371^{* *}$ & $-2.341^{* *}$ & $-2.237^{* *}$ & (6) & $-2.457^{* *}$ & $(27)$ & $-2.435^{* *}$ \\
\hline 6-month & $-1.877^{*}$ & $-1.898^{*}$ & $-1.742^{*}$ & $-1.643^{*}$ & $-1.672^{*}$ & (8) & $-1.877^{*}$ & (23) & $-1.727^{*}$ \\
\hline 12-month & $-1.798^{*}$ & $-1.816^{*}$ & $-1.680^{*}$ & -1.577 & -1.590 & (3) & $-1.771^{*}$ & (19) & -1.598 \\
\hline \multicolumn{10}{|l|}{$\mathrm{DM}$} \\
\hline 1-month & $-1.696^{*}$ & $-1.838^{*}$ & $-2.040^{* *}$ & $-1.973^{* *}$ & $-1.784^{*}$ & $(38)$ & $-1.803^{*}$ & (47) & $-1.824^{*}$ \\
\hline 3-month & -1.166 & -1.346 & -1.544 & -1.408 & -1.323 & (6) & -1.166 & (48) & -1.263 \\
\hline 6-month & -1.006 & -1.173 & -1.254 & -1.060 & -1.077 & (48) & ) -0.959 & (48) & -0.959 \\
\hline 12-month & -1.069 & -0.975 & -1.324 & -1.244 & -1.166 & (48) & -1.110 & (48) & -1.110 \\
\hline \multicolumn{10}{|l|}{$\mathrm{BP}$} \\
\hline 1-month & $-2.764^{* * *}$ & $-3.014^{* * *}$ & $-2.986^{* * *}$ & $-3.160^{* * *}$ & $-3.097^{* * *}$ & (43) & $-3.049^{* * *}$ & $(42)$ & $-3.117^{* * *}$ \\
\hline 3-month & $-2.821^{* * *}$ & $-3.217^{* * *}$ & $-3.042^{* * *}$ & $-3.143^{* * *}$ & $-2.835^{* * *}$ & $(45)$ & $-2.702^{* * *}$ & $(45)$ & $-2.702^{* * *}$ \\
\hline 6-month & $-2.620^{* * *}$ & $-2.980^{* * *}$ & $-2.743^{* * *}$ & $-2.713^{* * *}$ & $-2.541^{* *}$ & (26) & $-2.836^{* * *}$ & $(43)$ & $-2.536^{* *}$ \\
\hline 12-month & $-2.308^{* *}$ & $-2.569^{* *}$ & $-2.691^{* * *}$ & $-2.593^{* * *}$ & $-2.475^{* *}$ & (6) & $-2.304^{* *}$ & (15) & $-2.541^{* *}$ \\
\hline \multicolumn{10}{|l|}{$\mathrm{FF}$} \\
\hline 1-month & $-9.893^{* * *}$ & $-8.030^{* * *}$ & $-6.347^{* * *}$ & $-4.230^{* * *}$ & $-4.187^{* * *}$ & (48) & $-3.727^{* * *}$ & (47) & $-3.803^{* * *}$ \\
\hline 3-month & $-5.335^{* * *}$ & $-4.267^{* * *}$ & $-3.787^{* * *}$ & $-3.054^{* * *}$ & $-3.025^{* * *}$ & (47) & $-2.758^{* * *}$ & (47) & $-2.758^{* * *}$ \\
\hline 6-month & $-3.527 * * *$ & $-3.194^{* * *}$ & $-2.918^{* * *}$ & $-2.434^{* *}$ & $-2.437^{* *}$ & $(37)$ & $-2.308^{* *}$ & $(46)$ & $-2.366^{* *}$ \\
\hline 12-month & $-2.759 * * *$ & $-2.765^{* * *}$ & $-2.607^{* * *}$ & $-2.202^{* *}$ & $-2.194^{* *}$ & $(48)$ & $-2.092^{* *}$ & (48) & $-2.092^{* *}$ \\
\hline \multicolumn{10}{|l|}{ IL } \\
\hline 1-month & $-9.416^{* * *}$ & $-6.804^{* * *}$ & $-5.454^{* * *}$ & $-4.230^{* * *}$ & $-4.222^{* * *}$ & (36) & -4.230 & (44) & $-4.222^{* * *}$ \\
\hline 3-month & $-4.881^{* * *}$ & $-4.068^{* * *}$ & $-3.794^{* * *}$ & $-3.534^{* * *}$ & $-4.026^{* * *}$ & (38) & $-3.886^{* * *}$ & (38) & $-3.886^{* * *}$ \\
\hline 6-month & $-3.271^{* * *}$ & $-3.280^{* * *}$ & $-3.475^{* * *}$ & $-3.561^{* * *}$ & $-4.020 * * *$ & (9) & $-3.145^{* * *}$ & (44) & $-4.020 * * *$ \\
\hline 12-month & $-3.869 * * *$ & $-4.084^{* * *}$ & $-4.437^{* * *}$ & $-3.379 * * *$ & $-3.628^{* * *}$ & (35) & $-3.367^{* * *}$ & (45) & $-3.504^{* * *}$ \\
\hline \multicolumn{10}{|l|}{ JY } \\
\hline 1-month & $-4.151^{* * *}$ & $-2.621^{* * *}$ & $-2.431^{* *}$ & $-2.248^{* *}$ & $-1.872^{*}$ & (45) & $-1.929 *$ & $(48)$ & $-1.882^{*}$ \\
\hline 3-month & -1.558 & $-1.694^{*}$ & $-1.753^{*}$ & $-1.950^{* *}$ & $-2.045^{* *}$ & (11) & $-1.687^{*}$ & (45) & $-2.104^{* *}$ \\
\hline 6-month & -1.565 & $-1.765^{*}$ & $-1.727^{*}$ & $-1.822^{*}$ & $-1.909 *$ & (5) & -1.587 & $(42)$ & $-1.867^{*}$ \\
\hline 12-month & $-1.776^{*}$ & $-1.885^{*}$ & $-1.812^{*}$ & $-1.860^{*}$ & $-1.909^{*}$ & (6) & $-1.819^{*}$ & (14) & $-1.888^{*}$ \\
\hline
\end{tabular}

Notes: See notes in Table 1 for data details. The ADF-GLS (with demeaning) test is the one suggested by Elliott, Rothenberg, and Stock (1996) for an autoregressive unit root. MAIC is the modified Akaike information criterion proposed by $\mathrm{Ng}$ and Perron (2000) (the optimal lag order is given in parentheses). They have established that the MAIC criterion may provide huge size improvements in the ADF-GLS test. The sequential- $t$ criterion was proposed by $\mathrm{Ng}$ and Perron (1995) and is based on a sequential $t$ test on the highest order lag coefficient, stopping when that coefficient's $p$-value is less than 0.10 (the optimal lag order is given in parentheses). The superscripts ${ }^{* *},{ }^{* *},{ }^{*}$ indicate statistical significance at the $1 \%, 5 \%$, and $10 \%$ significance levels, respectively. 
Table 3. Johansen Likelihood Ratio (JLR) Test Statistics for Panels of Forward Exchange Premiums

\begin{tabular}{|c|c|c|c|c|c|c|}
\hline \multirow[b]{2}{*}{ Test Statistics } & \multicolumn{6}{|c|}{ Currency } \\
\hline & $\mathrm{CD}$ & $\mathrm{DM}$ & $\mathrm{BP}$ & FF & $\mathrm{IL}$ & JY \\
\hline \multicolumn{7}{|l|}{$\overline{\text { VECM Lag Order }}$} \\
\hline$k=4$ & $6.9431^{* * *}$ & $3.1597^{*}$ & $5.1703^{* *}$ & $5.1446^{* *}$ & $7.2956^{* * *}$ & $5.6532^{* *}$ \\
\hline$k=8$ & $7.5929 * * *$ & $2.9057^{*}$ & $6.3241^{* *}$ & $3.9037^{* *}$ & $6.9033^{* * *}$ & $4.7176^{* *}$ \\
\hline$k=12$ & $6.8290 * * *$ & $2.9373^{*}$ & $7.2779 * * *$ & $4.2312^{* *}$ & $7.3069^{* * *}$ & $5.2537^{* *}$ \\
\hline$k=16$ & $6.8389^{* * *}$ & $3.2820^{*}$ & $7.4198^{* * *}$ & $4.9927^{* *}$ & $10.0354^{* * *}$ & $5.6434^{* *}$ \\
\hline$k=20$ & $6.7268^{* *}$ & $3.1605^{*}$ & $7.0281^{* * *}$ & $5.7325^{* *}$ & $11.8057^{* * *}$ & $5.1830^{* *}$ \\
\hline$k=24$ & $6.3359^{* *}$ & $3.7850^{*}$ & $6.9564^{* * *}$ & $5.6178^{* *}$ & $12.8115^{* * *}$ & $4.9066^{* *}$ \\
\hline$k=28$ & $5.3881^{* *}$ & $4.2007^{* *}$ & $7.2744^{* * *}$ & $5.1464^{* *}$ & $15.1024^{* * *}$ & $5.1917^{* *}$ \\
\hline$k=32$ & $5.1568^{* *}$ & $4.1612^{* *}$ & $6.5859^{* *}$ & $5.1807^{* *}$ & $14.5531^{* * *}$ & $5.2263^{* *}$ \\
\hline$k=36$ & $5.5059 * *$ & $4.0656^{* *}$ & $6.6955^{* *}$ & $5.1872^{* *}$ & $11.7473^{* * *}$ & $4.7828^{* *}$ \\
\hline$k=40$ & $6.2722^{* *}$ & $3.6774^{*}$ & $6.6121^{* *}$ & $5.4867^{* *}$ & $10.9299 * * *$ & $4.6636^{* *}$ \\
\hline$k=44$ & $6.5094^{* *}$ & $3.8407^{*}$ & $6.4599 * *$ & $4.9605^{* *}$ & $11.3489^{* * *}$ & $4.5470^{* *}$ \\
\hline$k=48$ & $6.7830^{* *}$ & $3.7699 *$ & $7.2981^{* * *}$ & $5.9454^{* *}$ & $8.8869^{* * *}$ & $4.9078^{* *}$ \\
\hline
\end{tabular}

Notes: See notes in Table 1 for data details. Each panel consists of the forward premium series for each currency with contract maturities $m=1,3,6$, and 12 months (a total of four series). The null hypothesis in the JLR test is that at least one of the system variables under consideration is a unit-root process with the alternative being that all system variables are stationary processes. The Vector Error Correction Model (VECM) is estimated for various lag orders $k$ to ensure robustness of inference. The asymptotic distribution of the JLR test is $\chi^{2}(1)$; the critical value adjusted for finite-sample bias is given by $\chi^{2}(1) \frac{T}{T-p k}$, where $T$ is the number of observations, $p$ is the number of system variables (dimension of the system), and $k$ is lag order in the VECM. ${ }^{* * *}{ }^{* *}$, and ${ }^{*}$ indicate statistical significance at the 1,5 , and 10 per cent levels, respectively. Statistical significance is indicated in reference to adjusted critical values. 

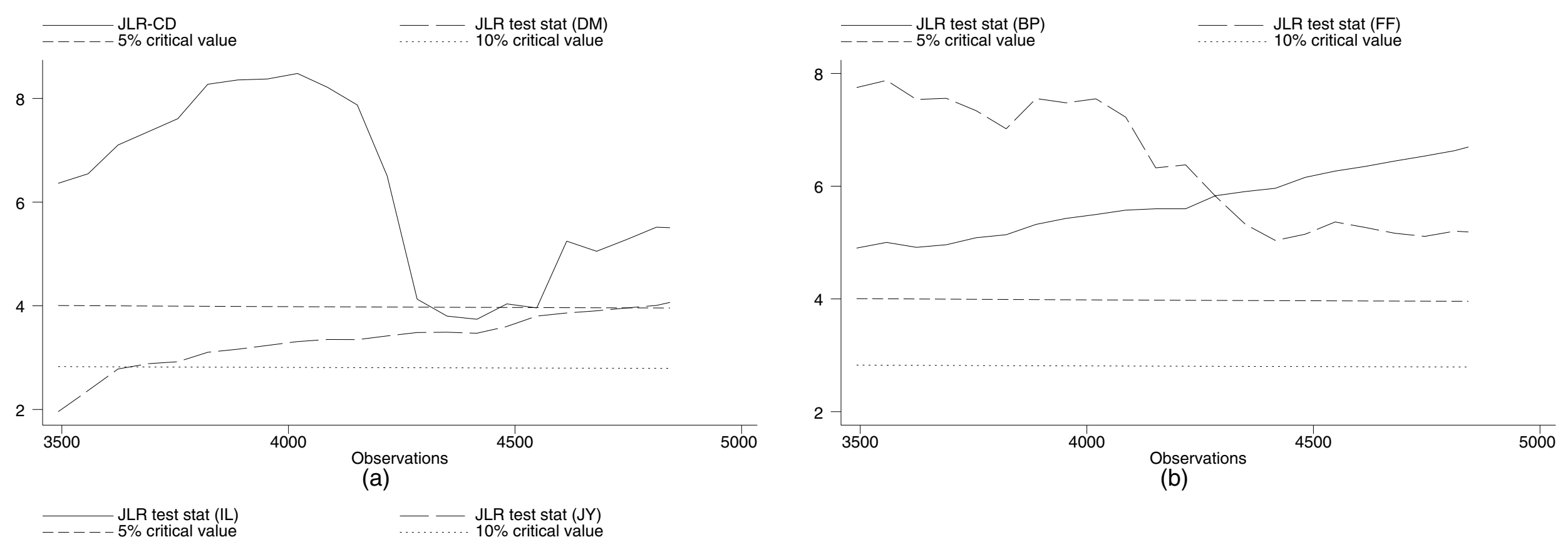

20

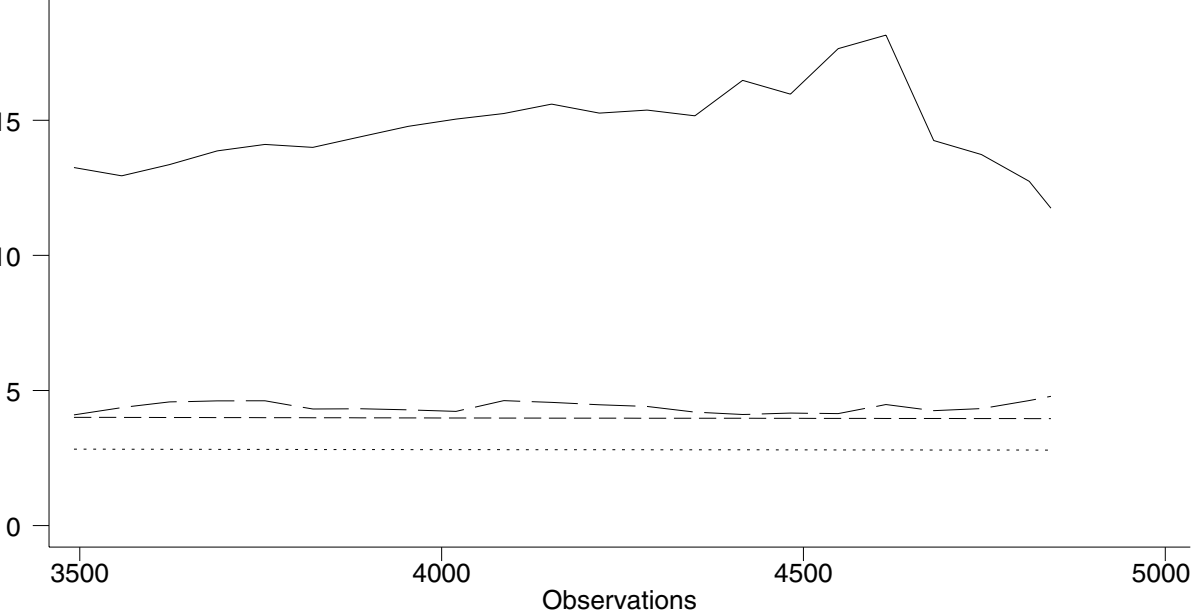

(c)

Figure 1: Recursive Estimates of JLR Statistic 